\title{
Transvaginal ultrasonography: a survey of the acceptability and its predictors among a native African women population
}

This article was published in the following Dove Press journal:

International Journal of Women's Health

28 December 2011

Number of times this article has been viewed

\author{
Omolola M Atalabi' \\ Imran O Morhason-Bello² \\ Ademola J Adekanmi' \\ Anthony O Marinho 3 \\ Babatunde O Adedokun ${ }^{4}$ \\ Adegoke $O$ Kalejaiye ${ }^{3}$ \\ Kayode Sogo ${ }^{3}$ \\ Sikiru A Gbadamosi ${ }^{3}$ \\ 'Department of Radiology; \\ ${ }^{2}$ Department of Obstetrics and \\ Gynaecology, College of Medicine/ \\ University College Hospital, \\ University of Ibadan, Ibadan; \\ ${ }^{3}$ St Gregory's Specialist Clinic \\ and Ultrasound Diagnostic Centre, \\ Yemetu, Ibadan; ${ }^{4}$ Department of \\ Epidemiology, Medical Statistics, and \\ Environmental Health, College of \\ Medicine, Ibadan, Nigeria
}

Objective: To determine the acceptability of transvaginal ultrasonography (TVU) and associated factors among Nigerian women.

Method: A cross-sectional survey was conducted among 3137 women who presented for transabdominal ultrasound scan between August and November 2010 in two referral hospitals in Nigeria. Data were obtained using a questionnaire. Descriptive and multivariate analysis was performed applying logistic regression analysis; predictors of willingness of participants regarding transvaginal ultrasound were identified using SPSS Statistics (SPSS Inc, Chicago, IL) version 17 software.

Results: The mean age of the women was 33.8 years (standard deviation $=7.9$ ), with $88.8 \%$ currently married. About $84 \%$ were willing to have TVU, while $54.2 \%$ were indifferent about the gender of the sonologist. About $17.3 \%$ believed that the procedure is painful. Significant predictors of willingness to have TVU were previous sexual experience and douching, prior painful vaginal examination, and vaginal surgery.

Conclusion: The majority of Nigerian women expressed a willingness to have the TVU procedure without necessarily opting for any gender preference of the operator. Women should be adequately counseled on the operations of the procedure so as to be able to psychologically prepare for them.

Keywords: transvaginal ultrasound, willingness, Nigeria, Africa

\section{Introduction}

Ultrasonography is one of the key radiological investigative tools that have positively impacted on the quality of diagnosis and subsequent medical care over the years. Traditionally, ultrasonic imaging of the abdomen and pelvis is performed using the transabdominal transducers. The wide acceptance of this technique is due to its safety and relative acceptability by the practitioners and end-users.

Transvaginal ultrasonography (TVU) was introduced to improve some observed drawbacks of the transabdominal approach, including poor imaging quality, interference by bowel gas, the discomfort of the mandatory full bladder, and it does not require any preparation, which is an added advantage in acute and emergency situations. ${ }^{1-5}$ The uses of TVU in pelvic ultrasound for gynecological and obstetric practice include ovulation monitoring, early diagnosis of normal pregnancy, embryonic demise, ectopic pregnancy, confirmation of embryonic viability diagnosis of spontaneous abortion, subchorionic hemorrhage, and molar pregnancy. ${ }^{3,6,7}$ It also allows for detailed examination and diagnosis of adnexal masses.

In spite of the current evidence that transabdominal scans can easily be performed with comparable accuracy without bladder filling, most sonologists in developing
Correspondence: Imran O Morhason-Bello Department of Obstetrics and Gynaecology, Faculty of Clinical Sciences, College of Medicine/University College Hospital, University of Ibadan, Ibadan, Nigeria

Tel +2348034784402

Email onembello@yahoo.co.uk
International Journal of Women's Health 201 2:4 I-6

(C) 2012 Atalabi et al, publisher and licensee Dove Medical Press Ltd. This is an Open Access article which permits unrestricted noncommercial use, provided the original work is properly cited.
Dovepress

http://dx.doi.org//0.2147/IJWH.S23533 
countries, including Nigeria, still adopt this practice, probably due to the poor quality of their ultrasound machine and/or lack of this new skill. ${ }^{8,9}$

In Nigeria, ultrasound was introduced about two decades ago, and it has been used for virtually all common indications reported elsewhere. ${ }^{10,11}$ The procedure is usually performed transabdominally, and it has enjoyed wide patronage and acceptability in both private and public settings. Most of the clientele are women that present for obstetrics or gynecological indications. Use of TVU began in Nigeria among private practitioners engaged in assisted conception, especially for pelvic organ evaluation and egg retrieval procedures, a few years ago. Even though this service is available especially in the tertiary hospitals, it may not be acceptable to the Nigerian female.

The acceptability and/or willingness to have TVU by the end-users have generated mixed reactions in different settings, and these observations have been reported in the literature. ${ }^{4,8,12}$ The willingness by the client ranges from $43 \%$ to $96 \%$, and this wide range in acceptance is said to be context specific. Factors that predict willingness include the age of participants, parity, previous painful vaginal examination and sexual violence, embarrassment from undue exposure, and loss of control. Other factors could also depend on the design of the study and the population of women used. Much as TVU is desirable, its introduction will therefore require censoring of clients' opinion to appreciate their feelings towards it. The findings of earlier studies on the willingness to have TVU, which were mostly performed in developed countries among the Caucasian population, may not apply in the African population. . $^{2,13}$

The rationale for this study is therefore premised on the paucity of data among the indigenous black population, so as to fill this critical gap in knowledge. The objective is therefore to determine the acceptability of TVU by Nigerian women and the predictors of the acceptability.

\section{Material and methods Study population}

This study was conducted amongst women who presented for elective obstetric and gynecological indicated ultrasonography. The pregnant women were referred for early antenatal scan, while the nonpregnant presented for benign gynecological indications.

\section{Setting}

This study was conducted in two centers, University College Hospital, Ibadan (UCH) - a tertiary center - and St Gregory's specialist clinic, Yemetu, Ibadan - a secondary center. The UCH serves as referral center for private and public primary and secondary health facilities within Nigeria. It was initially commissioned with 500 bed spaces in 1957, but presently the hospital has 850 beds and 163 examination couches. The current bed occupancy ranges from 55\% to $70 \%$. Yemetu performs predominantly diagnostic ultrasound scans. An average of 150 clients are seen per day, with the majority being women.

\section{Design}

This study was a cross-sectional survey conducted among women that presented for transabdominal ultrasound scans during the study period (August to November 2010). The participants in both centers were informed in groups about the uses of TVU, and this was buttressed with graphical representations of the TVU procedure as well as the type of probe that would be used. Consent to participate in the study was obtained individually after each had finished and collected their transabdominal scan result. Each participant then answered structured questions regarding their willingness to have TVU.

\section{Data collection}

The semi-structured questionnaire was initially pretested at a different facility to validate it. Thereafter, it was then administered to consenting women, by trained research assistants, in the waiting room of the two facilities. To ensure confidentiality, each consenting woman was interviewed separately in the waiting room. Participants were interviewed by trained research assistants on their sociodemographics, selected sexual history and practices, previous vaginal examination, and surgery. They were then asked whether they would be willing to have TVU for an indicated medical condition. The response was "yes" or "no."

\section{Statistical analysis}

The data obtained were coded and entered into SPSS Statistics (SPSS Inc, Chicago, IL) version 17 software. Bivariate analysis was performed using the chi-square test. Variables significant at $10 \%$ level were entered into the logistic regression model to identify likely biosocial predictors (including age, ethnic group, religion, occupation, and education) on their willingness to have TVU. The "enter" option of the variable selection procedures of the SPSS was used (a procedure which takes all variables in a block in a single step), and the level of statistical significance was set at $95 \%$ confidence levels. 


\section{Results}

There were 3200 participants approached for the study, of whom 3137 consented to participate, giving a response rate of $98 \%$. The number of women recruited at the $\mathrm{UCH}$ and Yemetu were 631 and 2506, respectively. The mean age and standard deviation were 33.8 and 7.9 years, respectively, with slightly less than half (47.8\%) aged between 25 and 34 years and $35.1 \%$ aged $35-44$ years (Table 1). The distribution of other selected sociodemographic variables is shown in Table 1. A large proportion of the women were currently married $(88.8 \%)$, while others were single, never married $(9.3 \%)$, separated $(1.1 \%)$, or widowed $(0.9 \%)$. The highest proportion $(56.6 \%)$ of respondents had tertiary-level education, followed by secondary $(34.5 \%)$, primary $(7.8 \%)$, and no formal education $(1.1 \%)$. The highest proportion of the women $(79.8 \%)$ was of the Yoruba ethnic group. There were 1757 (56\%) women who were aware of TVU. Concerning willingness to have TVU, 2618 women indicated a "yes" or "no" response, while the remaining 519 indicated "no response." Based on the 2618 providing a "yes" or "no"

Table I Percentage distribution of respondents' characteristics

\begin{tabular}{|c|c|c|}
\hline Variable & Frequency & $\%$ \\
\hline \multicolumn{3}{|l|}{ Location } \\
\hline $\mathrm{UCH}$ & 631 & 20.1 \\
\hline Ultrasound center & 2506 & 79.9 \\
\hline Total & 3137 & 100 \\
\hline \multicolumn{3}{|l|}{ Age (years) } \\
\hline Less than 25 & 263 & 8.4 \\
\hline $25-34$ & 1492 & 47.8 \\
\hline $35-44$ & 1096 & 35.1 \\
\hline $45+$ & 270 & 8.7 \\
\hline Total & $3|2|$ & 100 \\
\hline \multicolumn{3}{|l|}{ Education } \\
\hline None & 34 & I.I \\
\hline Primary & 241 & 7.8 \\
\hline Secondary & 1066 & 34.5 \\
\hline Tertiary & 1748 & 56.6 \\
\hline Total & 3089 & 100 \\
\hline \multicolumn{3}{|l|}{ Marital status } \\
\hline Single & 291 & 9.3 \\
\hline Married & 2777 & 88.8 \\
\hline Separated & 33 & I.I \\
\hline Widowed & 28 & 0.9 \\
\hline Total & 3129 & 100 \\
\hline \multicolumn{3}{|l|}{ Religion } \\
\hline Christianity & 2073 & 66.3 \\
\hline Islam & 1054 & 33.7 \\
\hline Total & 3127 & 100 \\
\hline \multicolumn{3}{|l|}{ Ethnicity } \\
\hline Yoruba & 2489 & 79.8 \\
\hline Others & 632 & 20.2 \\
\hline Total & $3|2|$ & 100 \\
\hline
\end{tabular}

International Journal of Women's Health 2012:4 response, $84 \%$ of women were willing to have TVU. Of those who indicated a willingness to have TVU, $37(1.7 \%)$ preferred a male health professional, 967 (44.1\%) preferred a female, and $54.2 \%$ were indifferent. A total of $542(17.3 \%)$ of all women studied felt that the TVU procedure would be painful, $13.7 \%$ indicated that it would not be painful, and the remaining $60 \%$ were not sure.

The predictors of willingness to have TVU such as sociodemographic characteristics and variables relating to sexual experience, vaginal examination, and instrumentation were investigated. Table 2 shows two sets of results from the analyses: (1) those from cross-tabulations between willingness to have TVU and selected variables, and (2) odds ratios (ORs) and confidence intervals (CIs) from logistic regression of willingness to have TVU. There were no significant associations between willingness to have TVU if indicated and any of the sociodemographic variables studied. The proportions indicating willingness were quite similar across age groups, different educational levels, marital status, religion, and ethnicity. Women attending the ultrasound center reported a higher willingness to have TVU compared with those at $\mathrm{UCH}(P=0.001)$. However, there was a significant association for previous sexual exposure, with higher proportions of those sexually experienced indicating they would have TVU if indicated $(P=0.007)$. Those who had suffered some form of sexual abuse were less willing than those who had not $(P=0.001)$, while women who practice vaginal douching were more in agreement with the TVU procedure compared with those who had never practiced douching $(P=0.001)$. There was a significant association between having had a painful vaginal examination and desire to have TVU; higher proportions were found for women who had never had a painful vaginal examination and those who never had a vaginal examination. Having had vaginal surgery $(P=0.009)$ and the perception that having an ultrasound scan is dangerous $(P<0.001)$ were also significantly associated with willingness to have TVU.

The variables entered into the logistic regression model all remained significant, except location. Those who had had sexual contact were about twice more likely to agree with having TVU if indicated than women who had not; women with history of sexual abuse about 1.7 times less likely than those with no such history; and those who had engaged in vaginal douching about 1.3 times more likely than those with no such practice. Those with history of painful vaginal examination were significantly less likely than those who never had a vaginal examination (OR 0.72, 95\% CI $0.55-0.95)$. History of vaginal surgery and perception 
Table 2 Association between willingness to have TVU if indicated, and variables

\begin{tabular}{|c|c|c|c|c|c|}
\hline \multirow[t]{2}{*}{ Variable } & \multicolumn{3}{|l|}{ Bivariate analysis } & \multicolumn{2}{|c|}{ Logistic regression analysis } \\
\hline & $\%$ willing to have TVU & $\mathbf{n}$ & Chi square ( $P$-value) & Odds ratio & $95 \% \mathrm{Cl}$ \\
\hline \multicolumn{6}{|l|}{ Location } \\
\hline Ultrasound centre & 85.1 & 2178 & 11.299 & 1.28 & $0.96-1.72$ \\
\hline $\mathrm{UCH}$ & 78.6 & 440 & $(0.001)$ & I & \\
\hline \multicolumn{6}{|l|}{ Age } \\
\hline Less than 25 & 81.3 & 208 & 5.653 & & \\
\hline $25-34$ & 85.4 & 1240 & $(0.130)$ & & \\
\hline $35-44$ & 82.4 & 942 & & & \\
\hline $45+$ & 86.2 & 218 & & & \\
\hline \multicolumn{6}{|l|}{ Level of education } \\
\hline None & 87.5 & 24 & 2.173 & & \\
\hline Primary & 83.6 & 201 & $(0.537)$ & & \\
\hline Secondary & 82.6 & 922 & & & \\
\hline Tertiary & 84.8 & 1434 & & & \\
\hline \multicolumn{6}{|l|}{ Marital status } \\
\hline Single never married & 80.0 & 225 & 2.895 & & \\
\hline Currently married & 84.3 & 2341 & $(0.235)$ & & \\
\hline Widowed/separated & 85.1 & 47 & & & \\
\hline \multicolumn{6}{|l|}{ Religion } \\
\hline Christianity & 84.7 & 1718 & 1.867 & & \\
\hline Islam & 82.6 & 892 & $(0.172)$ & & \\
\hline \multicolumn{6}{|l|}{ Ethnicity } \\
\hline Yoruba & 83.9 & 2077 & 0.180 & & \\
\hline Others & 84.6 & 527 & $(0.67 I)$ & & \\
\hline \multicolumn{6}{|l|}{ Ever had sex } \\
\hline Yes & 84.3 & 2545 & 7.250 & 1.76 & $1.02-3.05$ \\
\hline No & 72.6 & 73 & $(0.007)$ & 1 & \\
\hline \multicolumn{6}{|l|}{ Dyspareunia } \\
\hline Yes & 84.4 & 668 & 0.127 & & \\
\hline No & 83.8 & 1950 & $(0.722)$ & & \\
\hline \multicolumn{6}{|l|}{ Ever suffered sexual abuse } \\
\hline Yes & 77.0 & 269 & 11.065 & 0.60 & $0.44-0.82$ \\
\hline No & 84.8 & 2349 & $(0.001)$ & I & \\
\hline \multicolumn{6}{|l|}{ Practices vaginal douching } \\
\hline Yes & 86.1 & 1432 & 10.448 & 1.29 & $1.02-3.05$ \\
\hline No & 81.5 & 1186 & $(0.001)$ & I & \\
\hline \multicolumn{6}{|c|}{ Ever had painful vaginal examination } \\
\hline Yes & 80.3 & 471 & 7.331 & 0.72 & $0.55-0.95$ \\
\hline No & 83.5 & 690 & $(0.026)$ & 0.85 & $0.66-1.09$ \\
\hline Never had a vaginal examination & 85.4 & 1457 & & I & \\
\hline \multicolumn{6}{|c|}{ Ever managed for a vaginal condition } \\
\hline Yes & 83.7 & 490 & 0.046 & & \\
\hline No & 84.1 & 2128 & $(0.829)$ & & \\
\hline \multicolumn{6}{|l|}{ Ever had surgery in the vagina } \\
\hline Yes & 94.8 & 77 & 6.896 & 4.31 & $1.54-12.04$ \\
\hline No & 83.7 & 2541 & $(0.009)$ & I & \\
\hline \multicolumn{6}{|l|}{ Think ultrasound is dangerous } \\
\hline Yes & 68.1 & 47 & 52.291 & 0.43 & $0.23-0.82$ \\
\hline No & 87.0 & 1955 & $(<0.00 \mathrm{I})$ & I & \\
\hline Unsure & 75.8 & 616 & & & \\
\hline \multicolumn{6}{|l|}{ Ever had an ultrasound } \\
\hline Yes & 83.9 & 2248 & 0.035 & & \\
\hline No & 84.3 & 370 & $(0.852)$ & & \\
\hline
\end{tabular}

Abbreviations: $\mathrm{Cl}$, confidence interval; TVU, transvaginal ultrasonography; $\mathrm{UCH}$, University College Hospital, Ibadan, Nigeria. 
of ultrasound as being dangerous also remained significant predictors on logistic regression analysis. Those who had vaginal surgery were four times more likely than those who never had such procedure, and those who perceived ultrasound as dangerous were about 2.5 times less likely than other women to be willing to have TVU.

\section{Discussion}

The key finding from this study is that women in Nigeria like other parts of the world will accept TVU when it is necessary for their medical care. In this present study, $84 \%$ would agree to have TVU, this is within the range of $43 \%-96 \%$ reported in the literature. ${ }^{4,8,12}$ The probable explanation for the high willingness may be due to the general receptive attitude of Africans to medical services even when they are associated with some discomfort. Clement et al also mentioned this theory in a similar study where he suggested that the high acceptance rate might be due to their lack of confidence to refuse treatment compared with Caucasians. ${ }^{8}$ Another plausible reason for the high acceptance rate could be due to the higher proportion of respondents $(60 \%)$ that were not sure whether the TVU procedure is painful or not in contradistinction to the $17.3 \%$ that considers it painful.

The gender preference of the person that performs sensitive examination or procedure such as genital examination by women has been widely reported, with mixed outcomes. ${ }^{14,15}$ In this study, more than half were indifferent to the gender of the TVU operator, while 44 percent preferred their fellow woman, and very few wanted the male operator. This outcome is similar to other research findings elsewhere. It is however pertinent that the operator should abide by the guidelines governing the conduct of invasive procedures without minding the liberal disposition of the woman. Use of a chaperone, avoidance of indecent exposure, and maintenance of their privacy should be ensured at all times.

The significant predictors of willingness (ie, previous sexual experience, vagina douching, and prior vaginal surgery) positively predict participants that would accept TVU. One explanation for this association is that women who are sexually experienced or have had surgery may be more comfortable with vaginal procedures compared with other women. The finding of Bennett and Richards is contrary to this present study's outcome, as they found no strong association between previous sexual experience and violence with willingness to accept TVU. The difference in outcome could be due to the study design used; women in this present study answered "yes" or "no" to the question of willingness, whereas Bennett and Richards used the Likert scale approach, which could have blunted the absolute categorization of the predictors. ${ }^{13}$

On the contrary, history of sexual abuse, previous painful vaginal examination, and perception that ultrasound is a painful procedure were all associated with a lower willingness. It is possible that previous unpleasant and painful experience of events could continue to haunt their psychological wellbeing and as such could provoke a negative response and attitude towards TVU, as demonstrated in this study. This observation is in tandem with other studies that have established an association between women's resentment to pelvic examination in relation to their previous sexual violence. ${ }^{16,17}$ The perception of ultrasound as a painful procedure sounds interesting as the women's conclusions from mere visualization of TVU in this study speak volumes of clients' notions and perspectives towards medical investigations and treatment. It is therefore important that such views and other misconceptions are captured in the health education sessions/counseling to improve compliance and experience of the procedure.

Furthermore, in this study, none of the sociodemographic characteristics significantly influenced the participants' acceptability of TVU. This finding is also reported by other studies $^{13}$ whereas one study reported a linear relationship between willingness for TVU and some sociodemographics such as age and parity.

A limitation of this study is that none of the women used for this study had ever experienced the TVU procedure, and this could suggest that their opinions are based on visual and graphical representation of the procedure alone, thus limiting generalization of the study findings. In addition, the high acceptance rate could also be adduced to their participating in the study within the facility. Also, it is not clear whether or not pregnancy alone could influence willingness; this may be source of future research. However, the strong points of this study are as follows. First, this is the largest single study conducted on women's preferences towards TVU, and since this study has assessed the attitude that existed without prior experience of the procedure, it has given an opportunity to fully appreciate the significance of each of the predictors, unlike previous studies that use smaller sample sizes. Second, the study has added the perspective of black African women to the global data on this subject.

In conclusion, the study revealed that the majority of Nigerian women would be willing to have the TVU procedure without necessarily opting for any gender preference of the operator. In addition, their willingness is determined 
mostly by previous vaginal procedures or sexual exposure. The authors recommend that women should be adequately counseled on the operations of the TVU procedure, especially on categories of women that are not willing, so as to be able to psychologically prepare them. In addition, more studies should be conducted, especially on those that have had TVU procedures, to be able to capture their thoughts and also learn from their experiences in this setting with the hope of improving service delivery.

\section{Acknowledgments}

The authors appreciate the contribution of the health workers at the two centers in facilitating the smooth conduct of the study.

\section{Disclosure}

The authors report no conflicts of interest in this work.

\section{References}

1. Dashe JS, McIntire DD, Twickler DM. Maternal obesity limits the ultrasound evaluation of fetal anatomy. J Ultrasound Med. 2009;28(8): $1025-1030$.

2. Braithwaite JM, Economides DL. Acceptability by patients of transvaginal sonography in the elective assessment of the first-trimester fetus. Ultrasound Obstet Gynecol. 1997;9(2):91-93.

3. Chang MY, Chang SY, Soong YK. Transvaginal ultrasound-directed oocyte retrieval for in vitro fertilization. Taiwan Yi Xue Hui Za Zhi. 1989;88(7):689-693.

4. Rosati P, Guariglia L. Acceptability of early transvaginal or abdominal sonography in the first half of pregnancy. Arch Gynecol Obstet. 2000; 264(2):80-83.

5. Christensen JT, Thomsen SG. Transvaginal ultrasonography. Clinical applications. Ugeskr Laeger. 1993;155(25):1943-1948.
6. Cicero S, Skentou C, Souka A, To MS, Nicolaides KH. Cervical length at 22-24 weeks of gestation: comparison of transvaginal and transperineal-translabial ultrasonography. Ultrasound Obstet Gynecol. 2001;17(4):335-340.

7. Vercellini P, Cortesi I, Oldani S, Moschetta M, De Giorgi O, Crosignani PG. The role of transvaginal ultrasonography and outpatient diagnostic hysteroscopy in the evaluation of patients with menorrhagia. Hum Reprod. 1997;12(8):1768-1771.

8. Clement S, Candy B, Heath V, To M, Nicolaides KH. Transvaginal ultrasound in pregnancy: its acceptability to women and maternal psychological morbidity. Ultrasound Obstet Gynecol. 2003;22(5):508-514.

9. Guy RL, King E, Ayers AB. The role of transvaginal ultrasound in the assessment of the female pelvis. Clin Radiol. 1988;39:669-672.

10. Marinho AO, Bamgboye EA. Assessment of foetal femur length by ultrasound in a normal Nigerian obstetric population. Afr J Med Med Sci. 1987;16(2):47-52.

11. Osinusi BO, Ogunseyinde O. Ultrasonic foetal abdominal circumference as a means of assessing gestational age in Nigerians. Afr J Med Med Sci. 1989;18(2):101-104.

12. Dutta RL, Economides DL. Patient acceptance of transvaginal sonography in the early pregnancy unit setting. Ultrasound Obstet Gynecol. 2003;22(5):503-507.

13. Bennett CC, Richards DS. Patient acceptance of endovaginal ultrasound. Ultrasound Obstet Gynecol. 2000;15(1):52-55.

14. Schmittdiel J, Selby JV, Grumbach K, Quesenberry CP Jr. Women's provider preferences for basic gynecology care in a large health maintenance organization. J Womens Health Gend Based Med. 1999;8(6): 825-833.

15. Yanikkerem E, Ozdemir M, Bingol H, Tatar A, Karadeniz G. Women's attitudes and expectations regarding gynaecological examination. Midwifery. 2009;25(5):500-508.

16. Weitlauf JC, Finney JW, Ruzek JI, et al. Distress and pain during pelvic examinations: effect of sexual violence. Obstet Gynecol. 2008;112(6): 1343-1350.

17. Galasinski D, Ziolkowska J. Identity ambivalence and embodiment in women's accounts of the gynaecological examination. Health (London). 2007;11(4):455-474.
International Journal of Women's Health

\section{Publish your work in this journal}

The International Journal of Women's Health is an international, peerreviewed open-access journal publishing original research, reports, reviews and commentaries on all aspects of women's healthcare including gynecology, obstetrics, and breast cancer. Subject areas include: Chronic conditions (migraine headaches, arthritis, osteoporosis);

\section{Dovepress}

Endocrine and autoimmune syndromes; Sexual and reproductive health; Psychological and psychosocial conditions. The manuscript management system is completely online and includes a very quick and fair peer-review system. Visit http://www.dovepress.com/ testimonials.php to read real quotes from published authors. 